University of Nebraska - Lincoln

DigitalCommons@University of Nebraska - Lincoln

Faculty Publications from Nebraska Center for Research on Children, Youth, Families, and Schools
Children, Youth, Families \& Schools, Nebraska Center for Research on

$6-2010$

\title{
Young Children's Decisions to Include Peers with Physical Disabilities in Play
}

Karen E. Diamond

Purdue University - Main Campus, kdiamond@purdue.edu

Soo-Young Hong

University of Nebraska - Lincoln, shong5@unl.edu

Follow this and additional works at: https://digitalcommons.unl.edu/cyfsfacpub

Part of the Pre-Elementary, Early Childhood, Kindergarten Teacher Education Commons

Diamond, Karen E. and Hong, Soo-Young, "Young Children's Decisions to Include Peers with Physical Disabilities in Play" (2010). Faculty Publications from Nebraska Center for Research on Children, Youth, Families, and Schools. 26.

https://digitalcommons.unl.edu/cyfsfacpub/26

This Article is brought to you for free and open access by the Children, Youth, Families \& Schools, Nebraska Center for Research on at DigitalCommons@University of Nebraska - Lincoln. It has been accepted for inclusion in Faculty Publications from Nebraska Center for Research on Children, Youth, Families, and Schools by an authorized administrator of DigitalCommons@University of Nebraska - Lincoln. 


\title{
Young Children's Decisions to Include Peers with Physical Disabilities in Play
}

\author{
Karen E. Diamond \\ Purdue University, West Lafayette, Indiana, USA \\ Soo-Young Hong \\ University of Nebraska-Lincoln, Lincoln, USA
}

The authors examined factors related to preschool children's reasoning about including a hypothetical peer with a physical disability in different play activities. They hypothesized that children's inclusion decisions would be influenced by features of the physical environment, attention to issues of fairness and equity, and individual child characteristics. Participants comprised 72 children enrolled in inclusive preschool classrooms. Children's ideas about inclusion and their inclusion decisions were gathered in response to vignettes reflecting experiences that children are likely to encounter in preschool. The authors found that children were significantly more likely to say that they would include a child with a physical disability in an activity requiring few motor skills. Children's inclusion decisions were also significantly associated with their developing theory-of-mind skills and with prompts that encouraged them to consider issues of fairness and equity when making a decision. These results suggest that adaptations of planned activities that promote participation by reducing motor demands for all children, along with attention to issues of fairness and equity of opportunity, may be effective classroomwide interventions to support inclusion of children with disabilities in play activities with peers.

Keywords: Disabilities and development delays; Preschool inclusion; Early intervention issues; Multivariate statistics; Research methods; Preschoolers; Young children

About half of all preschool children with identified disabilities are educated in programs with their peers without disabilities (U.S. Department of Education, 2003), and approximately two thirds of 3-year-olds with identified disabilities attend center-based preschool or child care programs (Wall, Kisker, Peterson, Carta, \& Jeon, 2006). Young children are expected to develop socially and academically when they attend preschool programs with peers. Whereas young children's development of academic competence (e.g., early literacy and mathematics) has garnered considerable attention in recent years (National Research Council, 2001), children's social competence commands attention. Most states have identified learning standards for early childhood programs that include attention to children's development of social skills - particularly, social skills with peers (Scott-Little, Kagan, \& Frelow, 2006). The expectation is that preschool children, children with disabilities and 
children without identified disabilities, will develop the academic and social skills reflected in these early learning standards through participation in prekindergarten, Head Start, or private preschool programs, as well as in community activities. For children with disabilities, the potential of preschool settings to support peer-to-peer social competence is enhanced when there are opportunities to interact with peers without disabilities (Guralnick, Neville, Hammond, \& Connor, 2007).

Interactions with classmates in preschool offer opportunities for children to develop and expand their repertoire of peer-related social skills. Yet, research in inclusive preschool settings has consistently demonstrated that although children with disabilities are often included in play with classmates without identified disabilities, such play interactions occur less frequently for children with disabilities (Odom et al., 2006). Although teachers have reported that young children with disabilities have friends without disabilities (Buysse, Goldman, \& Skinner, 2002), observational data reveal that children with disabilities are chosen as playmates less frequently than their peers without disabilities (e.g., Brown, Odom, Li, \& Zercher, 1999). Even in high-quality programs, there is often considerable separation between children with disabilities and their classmates without disabilities when children's choices of play partners are not constrained by teacher-planned activities or the program structure (Guralnick, 1999).

In preschool, children's choices of play partners can be influenced by a number of different factors related to physical and social features of the preschool setting (Odom et al., 2006). For example, children's shared preferences for play activities may be related to opportunities for social interaction with peers who share similar interests, and teachers may use their knowledge of children's interests to encourage play among peers (Diamond \& Stacey, 2000). We know little, however, about factors associated with children's decisions about potential play partners. Understanding factors related to children's reasoning about including a peer with a disability in a specific play activity is a primary focus of the current study.

An important first question is whether preschool children have a sufficient understanding of any disability for it to play a role in their inclusion decisions. There is consistent research evidence demonstrating that children as young as preschool-age have a basic understanding of physical and sensory disabilities (Conant \& Budoff, 1983). Diamond (1994) found that preschool children distinguished among developmental competencies of photographed children with a physical disability when contrasted with photographs of children with no apparent disability. Children using a wheelchair or crutches were rated as being significantly less competent than their peers at tasks requiring motor skills (e.g., throwing a ball or climbing a ladder) but not at tasks with few physical demands, such as reading a book or listening to music. Nabors, Cohen, and Morgan (1994) found that preschool children's evaluations of an adult with an orthopedic impairment were different from their evaluations of an adult with no apparent disability. Similar results were reported by Magiati, Dockrell, and Logotheti (2002) in a study with slightly older children in Greece. These and other studies have been consistent in providing evidence that preschool children have a basic awareness of physical disability and recognize that someone using a wheelchair or crutches has difficulties with motor tasks.

In contrast to the evidence that preschool children are beginning to understand the implications of physical disability for participation in activities requiring motor skills, research evidence suggests that understanding of disabilities affecting cognition develops in late childhood and adolescence (Conant \& Budoff, 1983). Diamond and Hestenes (1996) found that preschool children did not recognize that a photographed child with Down syndrome 
had a disability that might interfere with participation in play. In the current study about inclusion decisions, we focus on children's reasoning about physical disabilities because of the consistent evidence that 4-year-olds understand the implications that physical disability might have for a child's participation in daily activities.

Preschool children's decisions to include a peer with a disability in a play activity might be influenced by the contexts in which decisions are made. Nabors and Keyes (1997) found that preschool children's preference ratings for a hypothetical child with a physical disability were more positive when the activity required modest physical skills (e.g., eating lunch) than when more robust motor skills were required (e.g., throwing a ball). Diamond and Tu (2009) confirmed these findings: Preschool children were more likely to say that they would include a hypothetical peer with a physical disability who used a wheelchair when the disability minimally interfered with participation. Understanding how children use information about activity contexts in making inclusion decisions might have important implications for our understanding of opportunities for social interaction in inclusive preschool settings. In this study, we focus on the activity setting as one of the contexts that might affect children's decisions to include a child with a physical disability in play.

Children's experiences in preschool are likely to inform their reasoning about inclusion (Diamond \& Stacey, 2000). Early childhood teachers socialize children's responses when they remind children of the importance of issues of fairness and equity in social relationships. In an observational study examining early childhood teachers' responses to children's transgressions, Killen and Smetana (1999) found that teachers were more likely to remind a child of the importance of being fair and considering others' feelings in response to moral transgressions, such as when there are limited resources and children need to take turns. When transgressions involved conventional issues, such as spilling juice at snack, teachers were more likely to either remind children of the importance of following classroom rules or use statements to indicate that a behavior was leading to classroom problems. Theimer, Killen, and Stangor (2001) provided evidence that preschool children attended to issues of fairness and equity in making decisions about playmates. In their study, when preschool children were presented with a hypothetical situation in which opportunities were unequal and thus unfair, children were most likely to say that they would include a child who had the fewest opportunities to participate in a play activity. In that study of gender-based inclusion decisions, issues of fairness and equity were more influential than gender stereotypes in children's inclusion decisions - for example, children were more likely to say that they would include a boy in doll play when the girl (not the boy) had previously played with dolls. In the present study, we prompted children's attention to issues of fairness and equity in their inclusion decisions by providing additional contexts in which a child with a disability did not have experience with specific play activities (Theimer et al., 2001).

Children's reasoning about how to resolve social dilemmas related to inclusion are likely to offer further insight into their inclusion decisions. Smetana (1995) argued that young children's judgments about how individuals should behave toward others reflect an awareness of moral and social-conventional rules. Theimer and colleagues (2001) found that preschool children referred to moral and social-conventional guidelines for evaluating and responding to hypothetical transgressions that involved excluding a child from a play group. We suggest that asking children to explain decisions to include a child with a physical disability in an activity may provide insight into the moral or social-conventional guidelines that inform their decisions. We hypothesize that highlighting issues of fair- 
ness and equity, as when a child with a disability has had few opportunities to play, will increase the likelihood that children say that they will include a peer with a disability. We hypothesize that children will be more likely to (a) explain a decision to include a child with a disability by referring to issues of fairness and equity, particularly in a situation in which the child with a disability has had less experience, and (b) refer to conventional explanations, such as a focus on ability, to explain their choice of a peer without a disability. It is not clear that issues of equity will be more important than issues related to the demands of the activity in children's decisions.

In addition to contextual factors that may influence children's inclusion decisions, individual child characteristics are likely related to children's social reasoning. There is substantial evidence that "an important conceptual change in children's understanding of persons" takes place between the ages of 2.5 and 5.0 years (Wellman, Cross, \& Watson, 2001, p. 673). This developmental change, referred to as children's development of theory of-mind skills, occurs in children's ability to see themselves and others in terms of mental states. That is, children develop an understanding that another person's actions are a result of emotions, beliefs, and intentions that are shaped by individual experiences and thus may be different from one's own perspective (Wellman et al., 2001). Theory-of-mind skills enable a child to understand that different experiences lead an individual to hold different beliefs and realize that people vary in what they know and believe. Thus, children who have developed theory-of-mind skills are potentially able to appreciate individual differences and so make appropriate assessments of another's knowledge or beliefs within the context of a particular task (Miller, 2002). Researchers have argued that theory of mind is a powerful social tool that leads to fundamental changes in children's interactions with others (e.g., Astington \& Jenkins, 1995; Jenkins \& Astington, 1996), just as the absence of theory-ofmind skills is associated with striking difficulties in social interaction, as seen in studies of children with autism (Mundy \& Crowson, 1997).

Recent studies provide support for hypothesized relations between theory-of-mind abilities and children's social competence. Watson and colleagues (Watson, Nixon, Wilson, \& Capage, 1999) found that children's theory-of-mind skills were a significant predictor of teachers' ratings of preschool and kindergarten children's social skills (but not popularity), even after the effects of age and language competence were considered. In a study of relationships among theory of mind, affective perspective taking, language skills, moral sensitivity, and friendship interactions, Dunn and colleagues (Dunn, Cutting, \& Demetriou, 2000) found that theory-of-mind skills and affective perspective taking accounted for significant and independent amounts of the variance in 4-year-olds' use of interpersonal justifications, rather than conventional rules, to explain their views about transgressions involving their friends (Dunn et al., 2000). These results are similar to those of Watson and colleagues (1999), who proposed that a child's ability to appreciate and evaluate multiple perspectives on a given situation and to posit causal relationships between events (past, present, and future) and behaviors might enhance the child's ability to guide behavioral reactions. There is substantial evidence that children's understanding that others have thoughts and feelings that are different from their own, as captured by theoryofmind skills, is related to more complex social reasoning and more successful social relationships. We hypothesize that theory-of-mind skills will moderate associations between activity settings and inclusion decisions, with children with more well-developed theoryof-mind skills being more likely to say that they will include a child with a physical disability. 


\section{Current Study}

The current study is designed to explore the effects of contextual factors and individual characteristics on preschool children's inclusion decisions. We examine questions related to the influence of features of the physical environment and issues of fairness and equity on children's decisions to include a child with a physical disability in different play activities. We focus on physical disability rather than higher-incidence disabilities because of the consistent evidence that preschool children have a beginning understanding of physical, but not cognitive, disability. This study addresses the following research questions:

Research Question 1: To what extent are physical demands of the activity context related to children's decisions to include a child with a physical disability in play?

Research Question 2: Are children more likely to say that they would include a child with a disability when issues of fairness and equity are highlighted?

Research Question 3: Do children's theory-of-mind skills moderate associations between setting characteristics (e.g., task difficulty, child experience) and their inclusion decisions?

Research Question 4: Are children more likely to refer to moral issues of fairness and equity than to conventional issues such as ability or disability to explain their decisions to include a child with a disability?

\section{Method}

\section{Participants}

Letters of invitation describing the research were sent to parents of all English-speaking 3- to 5-year-old children $(n=117)$, including children with disabilities, enrolled in seven inclusive classes in two preschool programs in a midsize Midwestern city. Seventy-two children $(62 \%)$ had permission to participate (37 girls; age: $M=51$ months, $S D=7.2)$, including 1 child identified as having a communication disorder. At the time of this study, 2 to 3 children in each of the seven classrooms had identified disabilities requiring an individualized education plan: 2 children had a pervasive developmental disorder or autism; 5 had a developmental delay; 8 had communication disorders; and 1 had spina bifida and walked using forearm crutches. As is common in community programs, no developmental assessment information was available for children without an individualized education plan. The average teacher:child ratio was 1:6.

\section{Procedure}

Each child was individually interviewed for 15 to 20 minutes in a small room away from the classroom. Children provided their assent before the interview began. We reminded each child that he or she could ask to stop the interview at any time. False-belief tasks assessing theory-of-mind skills were completed first, followed by the inclusion interview. Children's responses were recorded verbatim.

Three small wooden dolls, approximately 4-5 in. (10-13 cm) in height, were used to represent events in the false-belief tasks and for the inclusion interview. The dolls were the same sex as the participating child. Two dolls were used in the inclusion interview: one representing a child without a physical disability and one in a wheelchair representing a child with a physical disability. These were dolls that could be posed, and they were select- 
ed because they had knees that bent when seated in a wheelchair and because they were identical except for the color of their clothes. For false-belief tasks, we used one doll without a disability, along with appropriate props.

\section{Measures}

False belief. Four false-belief tasks (two change of location and two unexpected contents) were used to measure children's theory-of-mind skills (cf. Watson et al., 1999). The following is an example of the change-of-location task: The interviewer introduced a doll to the child and said, "This doll went shopping. She bought some goldfish crackers and brought them home. She put the goldfish crackers in the drawer before she went out to play. We are going to play a trick on the doll while she is out playing." The interviewer asked the child to help move the goldfish crackers from the drawer to a box and then said that the doll was ready to come inside from playing. The doll wanted to eat her goldfish crackers. The interviewer reminded the child that they had played a trick on the doll. Then the child was asked three questions: Where did the doll put her goldfish crackers before she went out to play? Where are the goldfish crackers now? Where will the doll look for the goldfish crackers? Each correct response received 1 point (possible range $=0-3$ for each of the two change-of-location tasks).

For an unexpected-contents task, the interviewer showed the child a crayon box and asked, "What do you think is inside this box?" After the child answered, the interviewer opened the box and showed the child that the box had candles in it. The interviewer closed the box and asked again, "Now what do you think is inside this box?" Then the interviewer introduced a doll to the child by saying, "The doll has never seen this box before. What would she think is inside the box before I take the lid off?" After the child answered, the interviewer again asked, "What did you think was inside the box before I opened it and showed you?" Each correct response received 1 point (possible range $=0-4$ for each of the two unexpected-contents tasks). Scores on the theory-of-mind tasks were summed (4 tasks, 14 questions, possible range $=0-14 ; \mathrm{a}=0.77$ in this sample).

Inclusion interview. The inclusion interview began with a warm-up task to ensure that the child understood that one doll could walk and that the other could not but used the wheelchair to move around. The interviewer introduced two dolls to the child and said, "Look at these dolls. Let's pretend these two dolls are real kids. I am going to tell you some stories about them and ask you some questions." Then the interviewer asked the child, "Can you tell me which child cannot walk?" If the child answered correctly, the interviewer said, "That's right. This doll cannot walk because her legs do not work. She uses her wheelchair to move around." If the child answered incorrectly $(n=4)$, the interviewer said, "Here [pointing to the doll in the wheelchair] is the doll who cannot walk because her legs do not work. She uses his wheelchair to move around." The child was then asked again to identify the doll that could not walk, and all children identified the doll in the wheelchair.

We used four vignettes that asked children to decide which one of two children should be included in a play activity: a hypothetical peer with a physical disability who used a wheelchair or a peer without physical disabilities. Physical disability interfered with a child's participation in two vignettes (kicking a ball, dancing); the child's disability did not substantially interfere in the other two vignettes (painting, playing with tabletop toys). The presentation order alternated by activity type, beginning with kicking a ball (disability interferes), followed by vignettes portraying painting, dancing, and tabletop toys.

For each vignette, the ongoing activity was described first. For example, the interview- 
er said that a few children were dancing to some music with the teacher. Children were shown two dolls and told that both dolls wanted to dance. We offered a suggestion for adapting the activity so that both children could participate (e.g., "Both of them can dance by moving their arms" or "Both of them can throw the ball"). Children were then asked two questions: "If there was only room for one more child, who [pointing to the two dolls] do you think should get to play?" and "Why did you choose this doll?" This is the baseline condition in which the only difference between the dolls is that of physical ability. After the child responded, we described a situation in which the child without a disability had participated in the activity but the child with a physical disability had not - for example, "This kid [pointing to the doll without a disability] has danced a lot before, but this kid [pointing to the doll in the wheelchair] has never danced before." This is the unequal experience condition in which the doll in the wheelchair always had less experience with an activity than did the doll without a disability. We were interested in whether the additional information about previous experience would play a role in children's inclusion decisions. We did not include a condition in which the doll in the wheelchair had more experience, because we were more interested in understanding whether highlighting issues of fairness would increase inclusion of the doll in the wheelchair. Children were then asked to make a choice about who should get to play and, again, justify their decision. If the child responded, "I do not know" or offered no response, the interviewer repeated the story and question, at most, two additional times. Responses were coded 1 if the child chose the doll using the wheelchair.

Data reduction. Based on the work of Killen and Stangor (2001), each justification was coded to reflect conventional or moral reasoning. Conventional justifications included those that reflected social order and conventional expectations, including the presence of equipment ("She can't because she's in the wheelchair") or differences in ability ("He can't play because he can't kick"). Justifications that relied on previous experience ("She should do it because she's done it before") were also coded as conventional justifications because they reflected implicit attention to a child's ability to engage in the activity. Moral justifications included those that reflected ideas of fairness and equity ("She should get to dance because she's never done it before"), turn taking ("Now it's his turn"), and adaptation ("He can't kick, but he can throw the ball"). Several children gave responses that included both hypothetical playmates ("We can get another chair so that there's room for everybody").

Those responses were coded as reflecting moral justifications because of the child's implicit focus on equity. Because we were interested in children's use of moral justifications rather than conventional ones, we counted the number of moral and nonmoral justifications and used these in our analyses. (Nonmoral justifications included conventional justifications and responses such as "I don't know.") All responses were independently coded by the second author and a research assistant. Overall agreement on whether a justification was moral was $94 \%$. All disagreements were resolved through discussion, and the final decision was used in analyses.

\section{Results}

\section{Data Analyses}

We examined all scores for skewness and kurtosis. Scores were normally distributed, with the exception of children's theory-of-mind scores, where there was a bimodal distribution. As a consequence, we dichotomized theory-of-mind scores at the midpoint of 9 ( $n$ $=35$ children with scores $<9$ ). 
In preliminary analyses, we found that children were significantly more likely to say that they would choose the doll without a physical disability $(68.4 \%$ of their choices) than the doll in the wheelchair as their playmate, $t(71)=-5.36, p<0.001, d=1.26$, across all contexts (kicking a ball, painting, dancing, playing with tabletop toys). Children's age and gender were not significantly associated with their choices of a child with a physical disability or with their theory-of-mind skills (all $r<0.15$ ).

Research Question 1 (baseline condition in which physical demands of activity context were the focus) and Research Question 2 (issues of equity highlighted) were addressed using a $2 \times 2$ repeated measures analysis of variance (context: disability interfered versus minimal interferences; experience: baseline versus unequal experience). The dependent variable was the number of times that a child with a disability was chosen. The analyses revealed a statistically significant but small main effect of context, $F(1,70)=4.27, p<$ $0.05, \eta_{p}^{2}=0.06$, and a statistically significant and medium effect of information about unequal experience, $F(1,70)=20.32, p<.001, \eta_{p}^{2}=0.22$. Partial eta squared $\left(\eta_{p}^{2}\right)$ provides an effect size estimate of the variance accounted for by the indicated factor and can be interpreted similarly to Cohen's $f^{2}$ (Cohen, 1988). Children were more likely to choose the peer with a disability (a) when the physical disability interfered minimally with the activity and (b) when they had information about the lack of experience of the peer with a disability. The interaction between activity context and experience was not statistically significant (see Table 1).

Research Question 3 (children's theory-of-mind skills) was examined using the previous $2 \times 2$ repeated measures analysis of variance, with children's theory-of-mind skills included as a between-subjects factor (low, high theory of mind). Results support our hypotheses: There was a statistically significant and small to medium main effect for theory of mind, $F(1,70)=12.54, p<0.001, \eta_{p}^{2}=0.15$. Children with low theory-of-mind skills were less likely to include a child with a disability across all eight opportunities ( $\mathrm{M}=1.6$ choices of a child with a disability, $\mathrm{SD}=1.9$ ) than were children with high theory-of-mind skills $(\mathrm{M}=3.4, \mathrm{SD}=2.3)$. Theory-of-mind skills moderated associations between context and experience conditions and inclusion decisions. Children with high theory-of-mind skills were more likely than other children to choose the doll with the disability when the physical disability minimally interfered with activity demands, $F(1,70)=8.89, p=0.004, \eta_{p}^{2}=$ 0.11 , or after receiving information about unequal experience, $F(1,70)=8.94, p=0.004, \eta_{p}^{2}$ $=0.11$ (see Table 2).

Research Question 4 (moral versus conventional issues) was addressed with a repeated measures analysis of variance, with frequency of moral explanations as the within-subjects repeated measure. Data from the 50 children who chose each doll at least one time were included in the analysis. The dependent variables were the frequencies with which a child used a moral explanation after choosing the doll without a disability and after choosing the doll in the wheelchair. Results of this analysis were statistically significant, $F(1,49)$ $=5.37, p<0.05, \eta_{p}^{2}=0.10$. Children were more likely to use moral justifications related to sharing and taking turns when they chose the doll in the wheelchair $(\mathrm{M}=0.30, \mathrm{SD}=0.36)$ than when they chose the doll without a disability $(M=0.19, S D=0.28)$. Notable as well was the substantial variability in justifications across children. 
Table 1

Activity Context, Experience, and Children's Inclusion Decisions $(n=72)$

$\begin{array}{llll} & \begin{array}{l}\text { Disability } \\ \text { Interferes }\end{array} & \begin{array}{l}\text { Disability } \\ \text { Interferes }\end{array} & \begin{array}{l}\text { Total Across } \\ \text { Disability }\end{array} \\ & \begin{array}{l}\text { Minimally } \\ \text { Conditions }^{\mathrm{b}}\end{array} & \text { Substantially }^{\mathrm{a}} & \begin{array}{l}\text { Cond } \\ \text { Baseline experience: No information }\end{array} \\ \text { Child with disability has less experience } & 0.53(0.77) & 0.33(0.58) & 0.86(1.15) \\ \text { Total across both experience conditions }^{\mathrm{b}} & 1.40(1.46) & 0.79(0.84) & 1.67(1.59)\end{array}$

Range $=0-2 \cdot{ }^{\text {b }}$ Range $=0-4$.

Table 2

Theory of Mind, Activity Context, Experience, and Children's Inclusion Decisions: Disability Interferes Minimally versus Substantially

\begin{tabular}{|c|c|c|c|c|}
\hline \multirow[b]{3}{*}{ Baseline experience: } & \multicolumn{2}{|c|}{ Low Theory of Mind, $n=35$} & \multicolumn{2}{|c|}{ High Theory of Mind, $n=37$} \\
\hline & Minimally & Substantially & Minimally & Substantially \\
\hline & $0.29(0.62)$ & $0.37(0.69)$ & $0.76(0.83)$ & $0.30(0.46)$ \\
\hline $\begin{array}{l}\text { Child with disability } \\
\text { has less experience }\end{array}$ & $0.46(0.74)$ & $0.49(0.71)$ & $1.27(0.87)$ & $1.08(0.86)$ \\
\hline
\end{tabular}

Note: Possible range of scores in each cell $=0-2$.

\section{Discussion}

The results of the current study provide further evidence that preschool children's ideas about inclusion are affected by a variety of factors, including disability, activity setting demands, and issues related to fairness and equity. Consistent with previous researchers (Favazza \& Odom, 1997; Nabors \& Keyes, 1997), we found that children are more likely to choose the doll representing a child without a disability than a child with a physical disability to join a play activity. This result is consistent with observational research suggesting that children with disabilities are excluded from play significantly more often than their peers without disabilities (Odom et al., 2006; Wolfberg et al., 1999). These findings are consistent, as well, with evidence that many preschool children, including children with communication disorders, prefer older more capable peers as play partners (Guralnick, Connor, Hammond, Gottman, \& Kinnish, 1996).

The results of this study provide evidence that preschool children are sensitive to demands of activity settings and to issues of fairness and equity when making a decision to include a child with a physical disability in play. We found that children are more likely to choose a child with a physical disability to join a play activity when the disability interferes minimally with participation. This finding suggests that children's inclusion decisions may be influenced in part by their implicit understanding of the demands of the play setting. These results are consistent with previous research (Diamond, 1994; Nabors \& 
Keyes, 1997) that revealed that even young children are aware that a physical disability interferes with some activities. This knowledge likely informs children's decisions, even when the adult suggests similar ways for both children to participate (e.g., by throwing a ball), as in this study.

In addition, children are more likely to include a child with a physical disability when they learn that this child has no experience with the activity and the other child does have experience. These results are consistent with work by Theimer and colleagues (2001), who used a similar paradigm to understand children's inclusion decisions in the context of gender-stereotyped activities. They found that children are more likely to choose the child who does not fit a gender stereotype when the nonstereotypical child has less experience with the play activity (e.g., a boy playing with dolls, a girl playing with trucks). In this study, the context was such that children's experiences were unequal; as such, it pit inclusion decisions based on issues of fairness and equity (Smetana, 1995) against decisions based on ability. By providing information about unequal experiences, we explicitly asked children to consider their decision in light of new information. Along with children's ideas about fairness, information about unequal experience might have influenced the frequency with which children decided to include the doll in the wheelchair because of the demand characteristics of the question.

In addition to finding factors associated with activity setting and experience, we found associations between children's developmental characteristics and their inclusion decisions. Children with moderately well-developed theory-of-mind skills appeared more sensitive to our manipulations of unequal experience and were more likely to include the doll in the wheelchair after receiving information about the child's lack of experience. Choosing to include a child with a physical disability after learning that the child has had little experience with an activity might reflect (a) children's understanding of another's desires and (b) their ability to think about issues related to inclusion from another's perspective (e.g., Jenkins \& Astington, 1996). In this study, children with well-developed theory-of-mind skills were more likely to say that they would include a child with a physical disability. Children with well-developed theory-of-mind skills were more likely to include a child with a physical disability when physical demands of the activity were modest; their inclusion decisions were also influenced by information about the other child's previous play experiences.

Children were more likely to use justifications related to fairness and equity to explain their decision to include the doll with the physical disability, although there was substantial variability in inclusion decisions and in justifications. Approximately two thirds of children included the child in the wheelchair on at least one occasion, and one child included the child every time. Helwig and Turiel (2002) argued that children's judgments and interpersonal reasoning are related to the ways in which they approach and frame their understanding of situations. As we noted, Killen and Smetana (1999) found that preschool teachers have many opportunities to refer to issues of fairness and equity in their interactions with children, particularly during choice time in the classroom. All the children in the present study were enrolled in inclusive classes with at least one classmate with a significant disability. Generalizing from Killen and Smetana's observations, we suggest that there should have been ample opportunities for teachers in these classrooms to offer reminders about the importance of sharing and fairness. Thus, children's preschool experiences in this case may have made them especially receptive to the dilemmas represented in the scenarios. 
Implications for Researchers

Important methodological issues challenge researchers who are interested in understanding young children's ideas about disability. It is difficult to identify a developmentally appropriate and understandable way to represent an individual's disability. In this study, we used a doll in a wheelchair to represent a child with a physical disability because young children are beginning to understand the implications of a physical disability for participation in some activities and because it is relatively easy to represent physical disability through the use of equipment. It is unclear how one might talk with young children about individuals with other, less apparent disabilities. A complementary approach is to talk with children about how they play with classmates, including classmates with disabilities. This has the advantage of eliciting children's insights about their experiences; the disadvantage is that children's ideas are likely to be closely linked to the personal characteristics of their peers. Developing appropriate strategies for eliciting young children's growing understanding of issues related to disability and interactions with peers is an area in need of further research attention.

The results of this study suggest that preschool children are sensitive to the physical demands of different activities and are more likely to include a child in a wheelchair in an activity in which physical expectations are modest. One implication is that interactions with peers with physical disabilities may increase children's understanding of the limitations likely to be associated with a disability. If that is the case, a consequence may be an increased likelihood that a child with a physical disability is excluded from play activities in contexts in which it is difficult to independently participate without teacher-implemented adaptations. Additional research is needed that examines associations between children's understanding of disabilities and inclusion of peers with disabilities across different play settings and activity contexts.

\section{Implications for Practitioners}

There is ample evidence that children with physical disabilities are at risk for exclusion. Yet, that children made different inclusion decisions in differing hypothetical play contexts suggests that a teacher's attention to physical demands of daily classroom activities might be one relatively low-cost initial classroomwide intervention that supports opportunities for peer social interaction (Brown, Odom, McConnell, \& Rathel, 2008). Adaptations that increase children's access to activities might be effective in supporting peer interaction - for example, moving a painting activity from an easel to a tabletop for all children, if there are some who find it difficult to stand and paint (Sandall \& Schwartz, 2008).

To the extent that children's reasoning is related to their actions, these results suggest that promoting sensitivity to issues of fairness and equity in preschool, along with child-focused social skills interventions, may promote interactions between children with disabilities and their peers without identified disabilities (e.g., Wolfberg et al., 1999). Whereas this approach requires explicit instruction by the teacher, this type of instruction is common in response to moral dilemmas in preschool classrooms (Killen \& Smetana, 1999).

Attending to issues of fairness and equity at the level of the individual child and the group and providing appropriate adaptations that allow children with disabilities to participate in the classroom curriculum (e.g., making a "You can't say, 'You can't play'" rule) are 
valuable classroomwide approaches for promoting opportunities for social interaction in inclusive preschool settings (e.g., Favazza \& Odom, 1997; Harrist \& Bradley, 2003). These types of experiences provide a developmentally appropriate foundation for enhancing understanding of others and encouraging interactions among classmates. Also important are more explicit social skills interventions that promote peer-peer interaction (Brown et al., 2008). Interventions that foster children's appreciation for individual differences, including those related to disability, may have an impact on attitudes and behaviors (DermanSparks and the ABC Task Force, 1989; Ostrosky \& Favazza, 2008).

Epstein (2007) highlighted the importance of "planful," intentional teaching, in which teachers plan supportive environments and use teaching strategies to support children's development of key learning goals. Although teachers often use an intentional approach for teaching academic skills, they can also adopt an intentional approach to supporting children's peer social relationships. Hollingsworth (2005) highlighted a number of effective intentional environmental strategies to support interactions among children with disabilities and their classmates without disabilities, including limiting the size of planned play groups and using materials that are familiar and likely to encourage social interactions (see also Diamond \& Stacey, 2000).

\section{Limitations}

As with any study, there are important limitations in our work. First, we do not know the extent to which children's behavior with peers is reflected in their responses to these scenarios. In a meta-analysis examining the effect of attitudes on future behavior, Glasman and Albarracin (2006) found that attitudes are more strongly associated with future behavior when people have direct experience with the attitude object (e.g., in this study, including children with a disability in play) and when conversations about their attitudes occurs frequently. This finding suggests that if children have more opportunities to talk about inclusion decisions at school and if the teacher intentionally and frequently provides ideas about possible ways to include another child in a play activity, children's ideas about inclusion may be related to their inclusive behaviors in the classroom. Because we did not observe children in their classrooms, we have no data that address this hypothesis.

Because the participants in this study were preschoolers, we limited our focus to inclusion decisions about hypothetical age mates with a physical disability. We focused on physical disability because of its salience to young children and because of previous evidence indicating that children have a basic understanding of the implications of physical disability for participation in different activities (Conant \& Budoff, 1983; Diamond, 1994; Magiati et al., 2002; Nabors \& Keyes, 1997). Therefore, we cannot make generalizations to children's attitudes toward a peer with a disability that is common but not as noticeable as "not being able to walk" (e.g., mental retardation, autism).

In summary, the results of this study suggest that preschool children are more likely to include a hypothetical peer with a physical disability in play activities when the play activities require fewer motor skills. Children's inclusion decisions are also influenced by their developing theory-of-mind skills and by prompts that promote them to consider issues of fairness and equity when making a decision. We note that in this study children were more likely to say that they would include the child with a physical disability when they learned that this child had less experience with an activity than did a peer. These results suggest 
that (a) adaptations of planned activities that promote participation by all children and (b) attention to issues of fairness and equity of opportunity might be effective classroomwide interventions to support inclusion of children with disabilities in play activities with peers.

\section{References}

Astington, J.W., and J.M. Jenkins (1995). Theory of mind development and social understanding. Cognition and Emotion 9: 151-165.

Brown, W.H., S.L. Odom, S. Li and C. Zercher (1999). Ecobehavioral assessment in early childhood programs: a portrait of preschool inclusion. Journal of Special Education 33: 138153.

Brown, W.H., S.L. Odom, S.R. McConnell and J.M. Rathel (2008). Peer interaction interventions for preschool children with developmental difficulties. In: W.H. Brown, S.L. Odom and S.R. McConnell (Eds.), Social Competence of Young Children: Risk, Disability, and Intervention (2nd ed., pp. 141-163). Baltimore: Brookes.

Buysse, V., B.D. Goldman and M.L. Skinner (2002). Setting effects on friendship formation among young children with and without disabilities. Exceptional Children 68: 503-517.

Cohen, J. (1988). Statistical Power Analysis for the Behavioral Sciences (2nd ed.). Hillsdale, N.J.: Erlbaum. Conant, S., \& Budoff, M. (1983). Patterns of awareness in children's understanding of disability. Mental Retardation 21: 119-125.

Derman-Sparks, L., and the ABC Task Force. (1989). Anti-Bias Curriculum: Tools for Empowering Young Children. Washington, D.C.: National Association for the Education of Young Children.

Diamond, K. E. (1994). Evaluating preschool children's sensitivity to developmental differences. Topics in Early Childhood Special Education 14: 49-63.

Diamond, K.E., and L. Hestenes (1996). Preschool children's conceptions of disabilities: the salience of disability in children's ideas about others. Topics in Early Childhood Special Education 16: 458-475.

Diamond, K.E., and S. Stacey (2000). The other children at preschool: Experiences of typically developing children in inclusive programs. In: S. Sandall \& M. Ostrosky (Eds.), Natural Environments and Inclusion (pp. 59-68). Frederick, Colo.: Sopris West.

Diamond, K.E., and H. Tu (2009). Relations between classroom context, physical disability and preschool children's inclusion decisions. Journal of Applied Developmental Psychology 30: 75-81.

Dunn, J., A.L. Cutting and H. Demetriou (2000). Moral sensibility, understanding others, and children's friendship interactions in the preschool period. British Journal of Developmental Psychology 18: 159-177.

Epstein, A.S. (2007). The Intentional Teacher: Choosing the Best Strategies for Children's Learning. Washington, D.C.: National Association for the Education of Young Children.

Favazza, P., and S.L. Odom (1997). Promoting positive attitudes of kindergarten-age children toward people with disabilities. Exceptional Children 63: 405-418.

Glasman, L.R., and D. Albarracin (2006). Forming attitudes that predict behavior: A metaanalysis of the attitude-behavior relation. Psychological Bulletin 132: 778-822. 
Guralnick, M.J. (1999). Family and child influences on the peer-related social competence of young children with developmental delays. Mental Retardation and Developmental Disabilities Research Reviews 5: 21-29.

Guralnick, M.J., R. Connor, M. Hammond, J.M. Gottman and K. Kinnish (1996). Immediate effects of mainstreamed settings on the social interactions and social integration of preschool children. American Journal on Mental Retardation 100: 359-378.

Guralnick, M.J., B. Neville, M.A. Hammond and R.T. Connor (2007). The friendships of young children with developmental delays: a longitudinal analysis. Journal of Applied Developmental Psychology 28: 64-79.

Harrist, A.W., and K.D. Bradley (2003). "You can't say you can't play": Intervening in the process of social exclusion in the kindergarten classroom. Early Childhood Research Quarterly 18: 185-205.

Helwig, C.C., and E. Turiel (2002). Children's social and moral reasoning. In: P.K. Smith and C.H. Hart (Eds.), Handbook of Childhood Social Development (pp. 475-490). Oxford, U.K.: Blackwell.

Hollingsworth, H.L. (2005). Interventions to promote peer social interactions in preschool settings. Young Exceptional Children 9(1): 2-11.

Jenkins, J.M., and J.W. Astington (1996). Cognitive factors and family structure associated with theory of mind development in young children. Developmental Psychology 32: 70-78.

Killen, M., and J. Smetana (1999). Social interactions in preschool classrooms and the development of young children's conceptions of the personal. Child Development 70: 486501.

Killen, M., and C. Stangor (2001). Children's social reasoning about inclusion and exclusion in gender and race peer group contexts. Child Development 72: 174-186.

Magiati, I., J.E. Dockrell and A.-E. Logotheti (2002). Young children's understanding of disabilities: the influence of development, context, and cognition. Journal of Applied Developmental Psychology 23: 409-430.

Miller, P.H. (2002). Theories of Developmental Psychology (4th ed.). New York: Worth.

Mundy, P., and M. Crowson (1997). Joint attention and early social communication: Implications for research on intervention with autism. Journal of Autism and Developmental Disorders 27: 653-676.

Nabors, L.A., R. Cohen and S.B. Morgan (1994). Becoming comfortable with an adult with an orthopedic handicap: Preschool children's behaviors in context. Journal of Applied Developmental Psychology 15: 489-500.

Nabors, L., and L. Keyes (1997). Preschoolers' reasons for accepting peers with and without disabilities. Journal of Developmental and Physical Disabilities 22: 113-122.

National Research Council. (2001). Eager to Learn: Educating Our Preschoolers. Washington, D.C.: National Academy Press.

Odom, S., C. Zercher, S. Li, J. Marquart, S. Sandall and W. Brown (2006). Social acceptance and rejection of preschool children with disabilities: a mixed-method analysis. Journal of Educational Psychology 98: 807-823.

Ostrosky, M., and P. Favazza (2008). Abstract: Establishing the efficacy of the "Special Friends" project. Washington, D.C.: Institute of Education Sciences.

Sandall, S.R., and I.S. Schwartz (2008). Building Blocks for Teaching Preschoolers with Special Needs. Baltimore: Brookes. 
Scott-Little, C., S.L. Kagan and V.S. Frelow (2006). Conceptualization of readiness and the content of early learning standards: The intersection of policy and research? Early Childhood Research Quarterly 21: 153-173.

Smetana, J.G. (1995). Morality in context: Abstractions, ambiguities, and applications. In: R. Vasta (Ed.), Annuals of Child Development (Vol. 10, pp. 83-130). London: Kingsley.

Theimer, C.E., M. Killen and C. Stangor (2001). Young children's evaluations of exclusion in gender-stereotypic peer contexts. Developmental Psychology 37: 18-27.

U.S. Department of Education (2003). Twenty-Fifth Annual Report to Congress on the Implementation of the Individuals with Disabilities Education Act. Retrieved April 3, 2006, from http://www.ed.gov/about/reports/annual/osep/2003/index.html

Wall, S., E.E. Kisker, C.A. Peterson, J.J. Carta and H.J. Jeon (2006). Child care for low-income children with disabilities: Access, quality, and parental satisfaction. Journal of Early Intervention 28: 283-298.

Watson, A.C., C.L. Nixon, A. Wilson and L. Capage (1999). Social interaction skills and theory of mind in young children. Developmental Psychology 35: 386-391.

Wellman, H.M., D. Cross and J. Watson (2001). Meta-analysis of theory-of-mind development: The truth about false belief. Child Development 72: 655-684.

Wolfberg, P.J., C. Zercher, J. Lieber, K. Capell, S. Matias, M. Hanson, et al. (1999). “Can I play with you?" Peer culture in inclusive preschool programs. Journal of the Association for Persons with Severe Handicaps 24: 69-84. 